$17^{\circ}$ ERGODESIGN

\& USIHC 2019

PUC-Rio, 11 a 13 de dezembro

Rio de Janeiro, RJ, Brasil $17^{\circ}$ Ergodesign - Congresso Internacional de Ergonomia e Usabilidade de Interfaces Humano Tecnológica: Produto, Informações Ambientes Construídos e Transporte

$17^{\circ}$ USIHC - Congresso Internacional de Ergonomia e Usabilidade

de Interfaces Humano Computador

\title{
ANÁLISE DE USABILIDADE EM GARRAFA TÉRMICA TIPO ROSCA
}

\author{
ANALYSIS OF USABILITY IN THERMAL THREAD BOTTLE
}

\author{
MARQUES, Arthur José Silva ${ }^{1}$ \\ Universidade Federal do Maranhão, Mestrando \\ arthurgarre@gmail.com
}

\section{SANTOS, Tayomara Santos dos 2}

Universidade Federal do Maranhão, Mestranda

Tayomara.ssantos@gmail.com

\author{
CAMPOS, Lívia Flávia de Albuquerque ${ }^{3}$ \\ Universidade Federal do Maranhão, Doutora \\ liviaflavia@gmail.com
}

\begin{abstract}
RESUMO
O presente artigo discorre sobre aspectos da usabilidade em modelos de garrafa térmica automática (IMETRO, 2016) que apresentam 'modo de servir' tipo Rosca e a influência destes no seu processo de abertura. Com isso, buscou-se identificar as dificuldades que os usuários possuem ao manusear este produto. Para isso, usamos como meio de investigação, a análise de realização da tarefa, observando as três métricas de usabilidade propostos por Jordan (1998), a eficiência, a eficácia e a satisfação. Por fim, pode-se perceber os desconfortos proporcionados pelos modelos e tipos de aberturas das garrafas térmicas, podendo assim, sugerir melhorias para este objeto.
\end{abstract}

usabilidade, garrafa térmica, mulheres

\section{ABSTRACT}

The present article discusses aspects of usability in automatic thermos models (IMETRO, 2016) that have a screw-type 'mode of serving' and their influence on its opening process. Thus, we sought to identify the difficulties that users have when handling this product. For this, we used as a means of investigation, the analysis of task accomplishment, observing the three usability metrics proposed by Jordan (1998), efficiency, effectiveness and satisfaction. Finally, one can see the discomforts provided by the models and types of openings of the thermos bottles, thus suggesting improvements for this object.

Usability, thermos bottle, women 


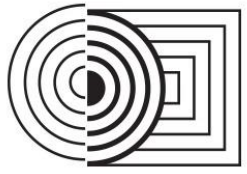

$17^{\circ}$ ERGODESIGN \& USIHC 2019

PUC-Rio, 11 a 13 de dezembro

Rio de Janeiro, RJ, Brasil $17^{\circ}$ Ergodesign - Congresso Internacional de Ergonomia e Usabilidade de Interfaces Humano Tecnológica: Produto, Informações Ambientes Construídos e Transporte

$17^{\circ}$ USIHC - Congresso Internacional de Ergonomia e Usabilidade de Interfaces Humano Computador

\section{INTRODUÇÃO}

A garrafa térmica é um recipiente, composto de uma parte externa (geralmente feita de polímero ou inox) e uma interna (ampola de vidro, plástico ou metal), ambas as partes unidas pelo gargalo. Este produto tem por objetivo manter o controle térmico do conteúdo da garrafa em relação à temperatura ambiente, com o intuito de preservar o alimento de maneira que permaneça adequado para o consumo. O físico-químico escocês James Dewar foi quem inventou, em 1892, o sistema de isolamento a vácuo, que é o princípio da garrafa térmica (INMETRO, 2016, p.05).

Apesar de Dewar ter sido o criador do sistema de isolamento a vácuo, o qual é utilizado no frasco de Dewar e nas garrafas atuais, ele não patenteou a invenção (Rodrigues, 2013, p.03). Em 1903, o alemão Reinhold Burger, um fabricante de vidros de Glashutte, patenteou a garrafa térmica para uso doméstico. As vantagens desse novo produto, destinado a conservar o calor e o frio, foram descobertas inicialmente pelos nobres e burgueses. Com isso, as garrafas térmicas passaram a ser indispensáveis nas caças, passeios de automóveis e de balão, e também como acessório de viagens (INMETRO, 2016, p.05).

Em virtude de sua simplicidade e a facilidade de transporte que oferecem, passaram a ter uma ampla utilidade. Hoje, as garrafas térmicas mais comuns são as de uso doméstico, que servem para manter líquidos quentes ou frios por longos períodos de tempo.

Segundo o INMETRO'1 (2016), as garrafas térmicas de uso doméstico são classificadas, basicamente, em dois tipos, automática ou com bomba, como discriminados a seguir:

a) garrafa térmica automática - popularmente denominada de garrafa térmica de rosca, é a garrafa dotada de tampa, que permite servir o líquido sem necessidade da retirada completa da tampa;

b) garrafa térmica com bomba - é a garrafa dotada de dispositivo de bombeamento, normalmente, incorporado à tampa, que permite servir o líquido sem que seja necessário incliná-la.

Elas também podem ser classificadas de acordo com o seu tipo ou uso. Garrafas térmicas de mesa, usadas em ambientes domésticos e laborais, e garrafas térmicas portáteis usadas para passeios e atividades físicas.

Segundo a Ouvidoria do INMETRO (2016), no período de 2013 a 2015, foi identificado que a maioria das reclamações referentes a garrafa térmica, tinham relação com a conservação, ou seja, tratavam da má conservação da temperatura dos líquidos. Já no período compreendido de 2007 a 2015 o Sistema Inmetro de Monitoramento de Acidentes de Consumo - SINMAC, disponível no site do INMETRO, registrou 10 (dez) ocorrências de acidentes com garrafas térmicas, a maioria delas associadas às queimaduras nas mãos, rosto e outras partes do corpo.

Nesse contexto, este artigo tem como objetivo identificar possíveis problemas de usabilidade no manuseio (processo de abrir) de garrafas térmicas automáticas com o 'modo de servir' ou 'modo de abertura' tipo Rosca. Para isso, analisamos aspectos da usabilidade propostos por Jordan (1998) em quatro modelos de garrafas térmicas domésticas, definidas em levantamento prévio como os mais utilizados.

1 INMETRO - Instituto Nacional de Metrologia, Qualidade e Tecnologia. 


\title{
2. USABILIDADE
}

Segundo Tullis e Albert (2008), várias são as definições encontradas na literatura para o termo usabilidade, praticamente uma para cada profissional que trabalha nessa área. Os autores relatam que, independente da definição adotada, sempre teremos: um usuário envolvido, que desenvolve alguma atividade; utilizando um produto, sistema ou alguma outra coisa. Krug (2000) em seu livro Don't make me think (Não me faça pensar), conceitua de forma clara e direita:

\begin{abstract}
Usabilidade significa tão somente garantir que algo funcione bem: que uma pessoa com habilidades e experiências médias (ou mesmo abaixo da média) possam usar a coisa - seja uma página na web, um caça a jato, ou uma porta giratória - para o seu propósito, sem ficar irremediavelmente frustrado (KRUG, 2000, pg.05).
\end{abstract}

A usabilidade quando mais direcionada ao desenvolvimento de produto é definida pela User Experience Professionals Association (UEPA) como:

Usabilidade é uma abordagem para o desenvolvimento de produtos que incorpora, de forma direta, o feedback do usuário ao longo do seu ciclo de desenvolvimento de forma a reduzir custos e a criar produtos e ferramentas que atendam às necessidades dos usuários (UEPA, 2019).

Segundo a NBR 9241/11, de agosto de 2002, define usabilidade como: a medida na qual um produto pode ser usado por usuários específicos para alcançar objetivos específicos com eficácia, eficiência e satisfação em um contexto específico de uso.

Para melhor entendimento desta definição, é necessário compreender o significado dos seguintes termos (NBR 9241-11, 2002; JORDAN, 1998):

- Eficácia: se refere à extensão na qual uma meta é alcançada ou uma tarefa é realizada;

- Eficiência: se refere à quantidade de esforço requerido para se atingir uma meta. Quanto menos esforço, maior é a eficiência;

- Satisfação: se refere ao nível de conforto que os usuários sentem quando utilizam um produto e também ao nível de aceitação do produto pelos usuários para atingir as suas metas.

Mediante as definições da NBR 9241-11 (2002) e de Jordan (1998) percebe-se que a usabilidade não é uma característica inerente do produto, para que esta ocorra, depende do seu "contexto específico de uso": quem está utilizando o produto; para que finalidade; em qual ambiente. $O$ contexto de uso diz respeito ao usuário, à tarefa, ao equipamento e ao ambiente em que o produto será utilizado. Todos esses fatores influenciam na seleção dos métodos, das métricas e do ambiente de avaliação da usabilidade (ROEPKE et al., 2012, pg.02).

\subsection{Métricas}

As métricas aplicadas à usabilidade referem-se à obtenção de indicadores quantitativos, relacionados à facilidade de utilização de um objeto. O objetivo é apontar esses indicadores 


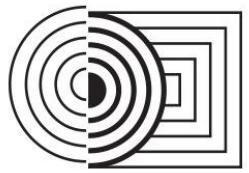

\section{$17^{\circ}$ ERGODESIGN \& USIHC 2019 \\ PUC-Rio, 11 a 13 de dezembro \\ Rio de Janeiro, RJ, Brasil}

$17^{\circ}$ Ergodesign - Congresso Internacional de Ergonomia e Usabilidade de Interfaces Humano Tecnológica: Produto, Informações Ambientes Construídos e Transporte

$17^{\circ}$ USIHC - Congresso Internacional de Ergonomia e Usabilidade de Interfaces Humano Computador

para formar um histórico, que, convenientemente analisado, identificará os possíveis problemas de usabilidade, além de orientar a tendência da evolução do objeto (TOSCANO, 2006, pg. 79).

Para o autor, as métricas de usabilidade são subjetivas, não possuem valores de grandezas. Os indicativos estão diretamente relacionados a experiência do usuário. E esta experiência é influenciada por fatores diversos, que dependem de características anatômicas, cognitivas, dentre outras. Esses fatores subjetivos, em um primeiro momento, podem ser "medidos" por tempo, tentativas de acertos e erros, ou seja, períodos gastos na execução de um processo específico.

Para Jordan (1998), as métricas utilizadas para a avaliação objetiva da usabilidade de um produto, relacionam-se com os três aspectos da usabilidade citados anteriormente.

- A primeira, a eficácia, deve ser medido pelo percentual de tarefas executadas corretamente em relação ao total de tarefas que devem ser realizadas.

- A segunda, a eficiência, deve ser medido pela relação da eficácia e do tempo total gasto pelo usuário para completar a tarefa.

- Por último, a métrica satisfação que identifica como determinados usuários realizam certas tarefas em um dado contexto de uso.

A satisfação é uma medida subjetiva quantificada por um questionário (BROOKE, 1996) que cobre diversos aspectos da usabilidade de produtos, como complexidade, necessidade de treinamento e consistência das informações (TOSCANO, 2006, pg.80).

\subsection{Manejo e pega}

Para Nordin e Frankel (2003), a mão é um órgão extremamente móvel, que coordena uma variedade de movimentos, também é a parte do membro superior que permite contato tátil entre o indivíduo e o ambiente. A preensão é uma das principais habilidades da mão. Borghi e Mejia (2016) completam informando que as preensões são controladas por dois grupos musculares concomitantemente: os músculos intrínsecos (localizados na própria mão, responsáveis pela maleabilidade e precisão) e os músculos extrínsecos (localizados no antebraço, responsáveis pela aplicação de forças e estabilidade do movimento). O funcionamento coordenado deste sistema muscular é essencial para o desempenho satisfatório da mão.

Quanto ao manejo, lida (2005) informa que trata-se de uma forma particular de controle, onde há o predomínio dos dedos e da palma da mão, pegando, prendendo ou manipulando alguma coisa. Conforme o autor, existem diversas classificações de manejo, mas, de uma forma geral, elas recaem sobre dois tipos que pode-se destacar:

- Manejo fino: é executado com as pontas dos dedos. É chamado também de manejo de precisão. Os movimentos são transmitidos principalmente pelos dedos, enquanto, a palma da mão e o punho permanecem relativamente estáticos.

- Manejo grosseiro: ou de força, é executado com o centro da mão. Os dedos têm a função de prender, mantendo-se relativamente estáticos, enquanto os movimentos são realizados pelo punho e braço. 
Imagem 01: Manejos segundo classificação de Itiro lida, 2005.

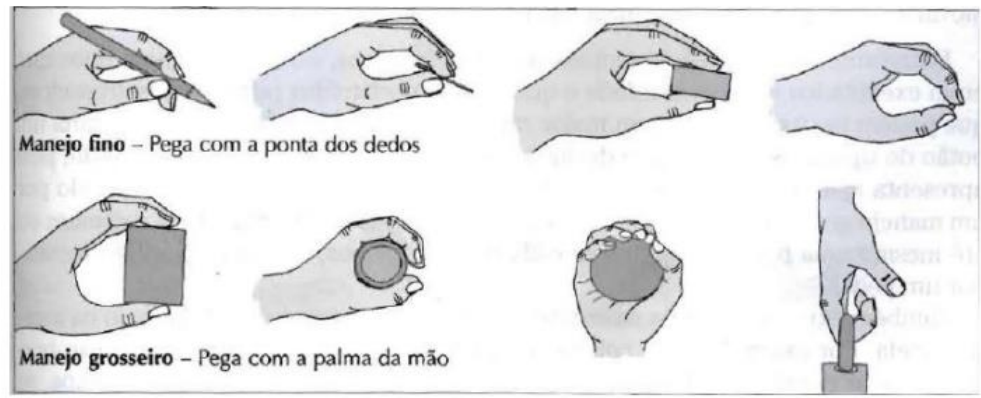

\section{PROCEDIMENTOS METODOLÓGICOS}

Iniciamos esse estudo com um levantamento sobre as garrafas térmicas domésticas e laborais mais utilizados no cotidiano das pessoas. Este levantamento foi realizado a partir de observações no campo no período de 02 a 04 de janeiro do ano corrente, em casas, estabelecimentos como restaurantes e lanchonetes e identificamos os seguintes modelos:

Imagem 02: Modelo de garrafas mais usadas.

Fonte: Autores, 2019.
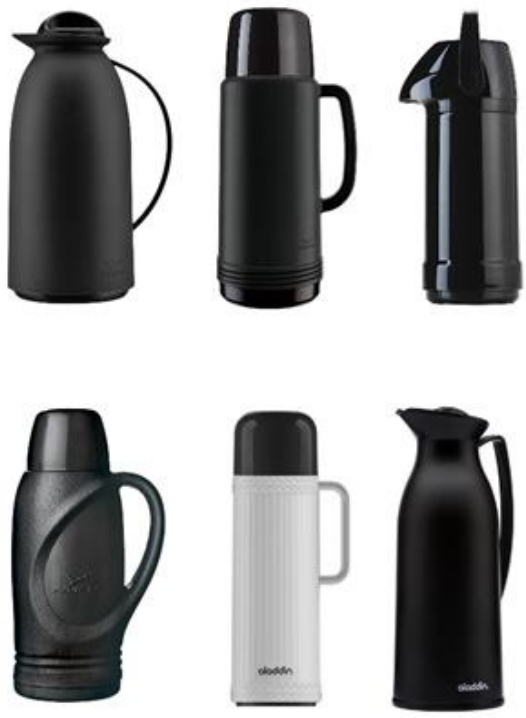

Dos seis modelos identificados como mais usados, cinco destes possuem como característica o modo de servir ou popularmente 'tampa' tipo rosca. Apenas um modelo tem como modo de servir 
o sistema por pressão. Após o levantamento, buscamos modelos de garrafas similares aos identificados previamente (mesmo sistema de abertura da tampa e modo de servir) e com o avanço da pesquisa, foram realizados testes preliminares para refinamento e estudo da avaliação a ser aplicada, buscando evitar os possíveis problemas que pudessem ocorrer durante a avaliação no teste definitivo.

\subsection{Objetos Pesquisados}

Com propósito de conseguir identificar as diferentes percepções no abrir, usamos 4 garrafas térmicas com características formais distintas, mas, com características similares as apresentadas no levantamento inicial:

Imagem 03: Garrafa Prima - A

Fonte: Autores, 2019.

\begin{tabular}{|l|l|}
\hline \multicolumn{2}{|c|}{ Especificações } \\
\hline Garrafa térmica Prima & Marca Obba - PRIMA \\
\hline & $1.0 \mathrm{~L}$ \\
\hline Capacidade (litro) & Rolha \\
\hline Sistema de servir & 6 horas \\
\hline Conservação térmica (quente) & 12 horas \\
\hline Conservação térmica (frio) & Polipropileno (PP) \\
\hline Material externo & Ampola vidro \\
\hline Material interno & 155 \\
\hline Comprimento $(\mathrm{mm})$ & 120 \\
\hline Largura $(\mathrm{mm})$ & 285 \\
\hline Altura (mm) & 0.534 \\
\hline Peso liquido $(\mathrm{kg})$ & 0.580 \\
\hline Peso bruto $(\mathrm{kg})$ & \\
\hline
\end{tabular}

Imagem 04: Garrafa Swan - B

Fonte: Autores, 2019.

\begin{tabular}{|l|l|}
\hline \multicolumn{2}{|c|}{ Especificações } \\
\hline Garrafa térmica Swan & Marca Invicta- SWAN \\
\hline Capacidade (litro) & $0.75 \mathrm{~L}$ \\
\hline Sistema de servir & Rolha \\
\hline Conservação térmica (quente) & 12 horas \\
\hline Conservação térmica (frio) & 24 horas \\
\hline Material externo & Polipropileno (PP) \\
\hline Material interno & Ampola vidro \\
\hline Comprimento $(\mathrm{mm})$ & 111 \\
\hline Largura $(\mathrm{m})$ & 12 \\
\hline Altura $(\mathrm{mm})$ & 272 \\
\hline Peso liquido $(\mathrm{kg})$ & 0.410 \\
\hline Peso bruto $(\mathrm{kg})$ & 0.438 \\
\hline
\end{tabular}


$17^{\circ}$ ERGODESIGN \& USIHC 2019

PUC-Rio, 11 a 13 de dezembro

Rio de Janeiro, RJ, Brasil $17^{\circ}$ Ergodesign - Congresso Internacional de Ergonomia e Usabilidade de Interfaces Humano Tecnológica: Produto, Informações Ambientes Construídos e Transporte

$17^{\circ}$ USIHC - Congresso Internacional de Ergonomia e Usabilidade de Interfaces Humano Computador

Imagem 05: Garrafa Pampa - C

Fonte: Autores, 2019.

\begin{tabular}{|l|l|}
\hline \multicolumn{2}{|c|}{ Especificações } \\
\hline \multicolumn{2}{|c|}{ Marca Alladin - PAMPA } \\
\hline Garrafa térmica Pampa & $1.0 \mathrm{~L}$ \\
\hline Capacidade (litro) & Rolha \\
\hline Sistema de servir & 12 horas \\
\hline Conservação térmica (quente) & 24 horas \\
\hline Conservação térmica (frio) & Polipropileno (PP) \\
\hline Material externo & Ampola plástico \\
\hline Material interno & 10 \\
\hline Comprimento $(\mathrm{cm})$ & 13,4 \\
\hline Largura $(\mathrm{cm})$ & 31,4 \\
\hline Altura $(\mathrm{cm})$ & 0.526 \\
\hline Peso liquido $(\mathrm{kg})$ & 0.534 \\
\hline Peso bruto $(\mathrm{kg})$ & \\
\hline
\end{tabular}

Imagem 06: Garrafa Lola - D

Fonte: Autores, 2019.

\begin{tabular}{|l|l|}
\hline \multicolumn{2}{|c|}{ Especificações } \\
\hline \multicolumn{2}{|c|}{ Marca OBBA - LOLA } \\
\hline Garrafa térmica Lola & $0.75 \mathrm{~L}$ \\
\hline Capacidade (litro) & Rolha \\
\hline Sistema de servir & 6 horas \\
\hline Conservação térmica (quente) & 12 horas \\
\hline Conservação térmica (frio) & Polipropileno (PP) \\
\hline Material externo & Ampola vidro \\
\hline Material interno & 160 \\
\hline Comprimento (mm) & 160 \\
\hline Largura (mm) & 250 \\
\hline Altura (mm) & 0.540 \\
\hline Peso liquido $(\mathrm{g})$ & 0.570 \\
\hline Peso bruto $(\mathrm{g})$ & \\
\hline
\end{tabular}


$17^{\circ}$ ERGODESIGN \& USIHC 2019

PUC-Rio, 11 a 13 de dezembro

Rio de Janeiro, RJ, Brasil $17^{\circ}$ Ergodesign - Congresso Internacional de Ergonomia e Usabilidade de Interfaces Humano Tecnológica: Produto, Informações Ambientes Construídos e Transporte

$17^{\circ}$ USIHC - Congresso Internacional de Ergonomia e Usabilidade

de Interfaces Humano Computador

Imagem 07: Classificação das Garrafas.

Fonte: Autores, 2019.

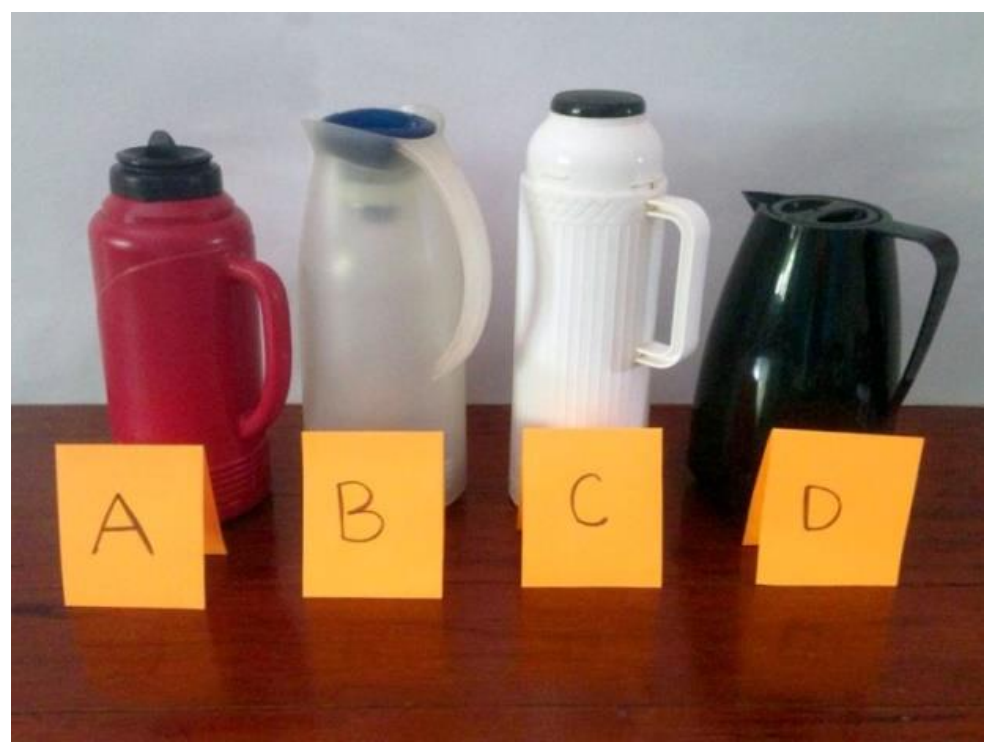

\subsection{Ambiente da pesquisa}

Os testes foram realizados em um ambiente controlado, com o intuito não apenas de manter a atenção do usuário sem a intervenção de elementos externos, mas para que também pudessem aproxima-lo de uma situação cotidiana de uso das garrafas. O usuário foi conduzido a uma mesa, onde os questionários e utensílios foram posicionados. 


\section{$17^{\circ}$ ERGODESIGN \& USIHC 2019}

PUC-Rio, 11 a 13 de dezembro

Rio de Janeiro, RJ, Brasil $17^{\circ}$ Ergodesign - Congresso Internacional de Ergonomia e Usabilidade de Interfaces Humano Tecnológica: Produto, Informações Ambientes Construídos e Transporte

$17^{\circ}$ USIHC - Congresso Internacional de Ergonomia e Usabilidade de Interfaces Humano Computador

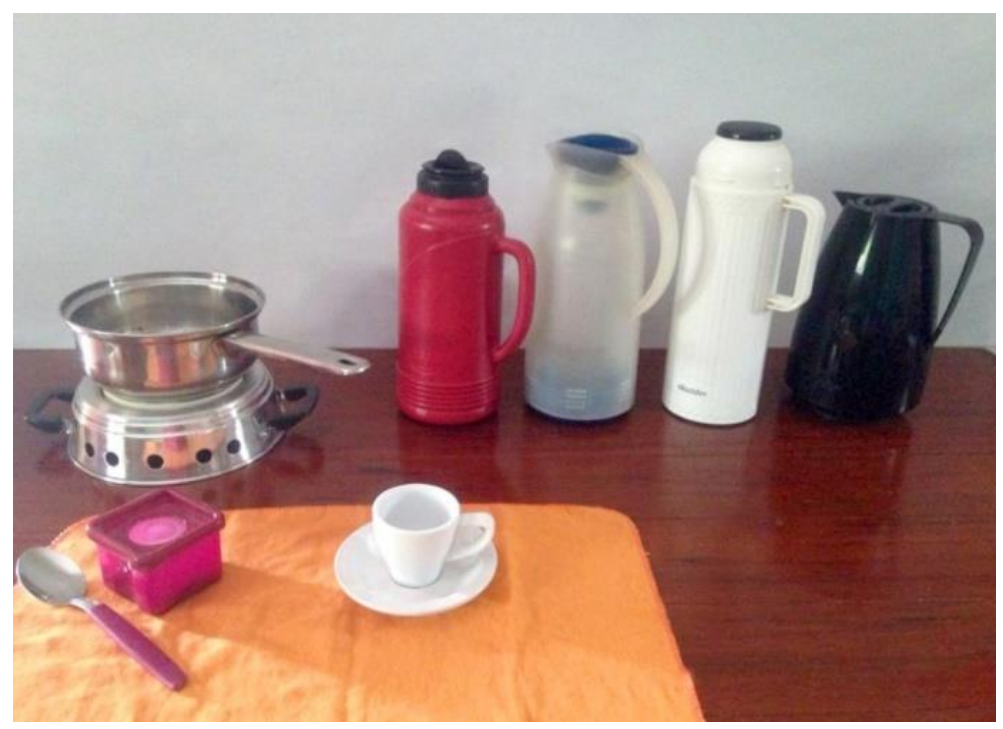

Como cenário para ilustrar a tarefa, pedimos às usuárias que simulassem o preparo de um café para o lanche da tarde. Para tanto, foram disponibilizados como materiais de apoio: um pequeno fogão artesanal cerâmico, um papeiro com água, um recipiente com pó de café, uma colher e para servir, xícara e pires. Concluído o teste, o moderador conduzia o usuário através do trajeto definido até a saída, para não que não houvesse intervenções dos outros usuários.

Imagem 09: Participante simulando passar café. Fonte: Autores, 2019.

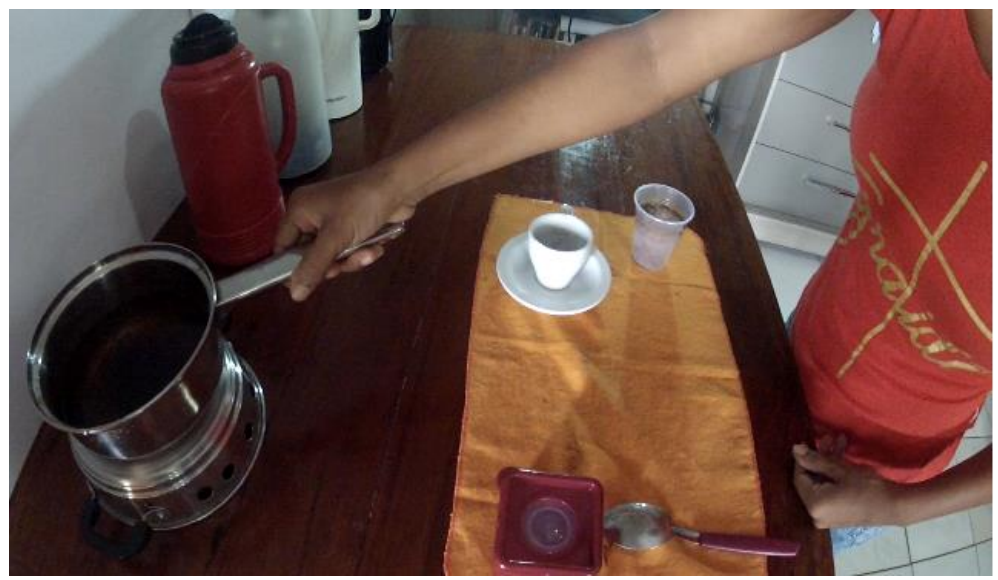

\subsection{Grupos pesquisados}

Para a realização dos testes, participaram voluntariamente 10 participantes do sexo feminino, destras, distribuídas em dois grupos por faixa etária: Grupo 1 - Mulheres com idade entre 18 a 29 anos (média de idade 25,4 anos). Grupo 2 - Mulheres com idade entre 30 e 50 anos (média de idade 43,4 anos). Todas usuárias de garrafas térmicas no cotidiano. 


\section{$17^{\circ}$ ERGODESIGN \& USIHC 2019 \\ PUC-Rio, 11 a 13 de dezembro Rio de Janeiro, RJ, Brasil}

$17^{\circ}$ Ergodesign - Congresso Internacional de Ergonomia e Usabilidade de Interfaces Humano Tecnológica: Produto, Informações Ambientes Construídos e Transporte

$17^{\circ}$ USIHC - Congresso Internacional de Ergonomia e Usabilidade de Interfaces Humano Computador

\subsection{Instrumentos de coleta de dados}

\subsubsection{Realização da Tarefa}

Com o intuito de identificarmos possíveis inconformidades durante o uso das garrafas térmicas, como dificuldades na abertura, desperdício do conteúdo da garrafa, entre outros fatores, traçamos tarefas que já fazem parte do cotidiano das usuárias, tais como:

1. Simular o preparo de um café;

2. Abrir a garrafa térmica e colocar o café no interior da garrafa;

3. Servir o café na xícara;

4. Fechar a garrafa após servir o café na xícara.

Cronometramos o tempo de realização da tarefa feita com cada um dos quatro modelos (A, B, $\mathrm{C}$ e D) de garrafa. O registro de cada tarefa realizada foi feito em fotografia e vídeo, para observações mais detalhadas.

\subsubsection{Protocolos}

O uso de protocolos é fundamental para captar dados importantes à pesquisa, logo usamos os seguintes documentos:

- Para expressar os objetivos do estudo e as implicações éticas de participação dos sujeitos no teste, fizemos uso do Termo de Consentimento Livre e Esclarecido TCLE.

- Protocolo Pré-teste (P01): compete ao documento, Protocolo de Identificação do usuário - para a coleta de informações e caracterização da amostra. Protocolo de experiência prévia do usuário - com o intuito de compreender a experiência do usuário com relação ao objeto deste estudo - garrafa térmica;

- Protocolo do nível de dificuldade do usuário (P02) - (dada por escala) após realização de todas as tarefas propostas;

- Protocolo de satisfação (P03) - adaptado do questionário SUS (System Usability Scale) de Stanton \& Barber (2002) para entender experiência do usuário após realização das tarefas com cada utensílio proposto;

- Protocolo de Percepção de desconforto/dor (P04) - adaptado de Kuijt-Evers² (2006), para identificar os possíveis locais de dor apontados pelas participantes.

\subsection{Análise dos dados}

Definimos dois grupos para a pesquisa: Grupo 1 (G1) - Mulheres com faixa etária entre 18 e 29 anos e o Grupo 2 (G2) Mulheres como faixa etária entre 30 a 50 anos. Todas as participantes são destras.

2 Método subjetivo para análise da percepção do desconforto, utilizam-se do mapa detalhado da mão. 
P01: Identificação e Experiência do usuário com garrafas térmicas domésticas.

Como primeira etapa de coleta de dados para esta pesquisa, aplicamos um protocolo de identificação e experiência prévia do usuário para estimarmos a relação deste com o objeto pesquisado - garrafa térmica de uso doméstico - logo, obtivemos os seguintes resultados:

Fonte: Autores, 2019.

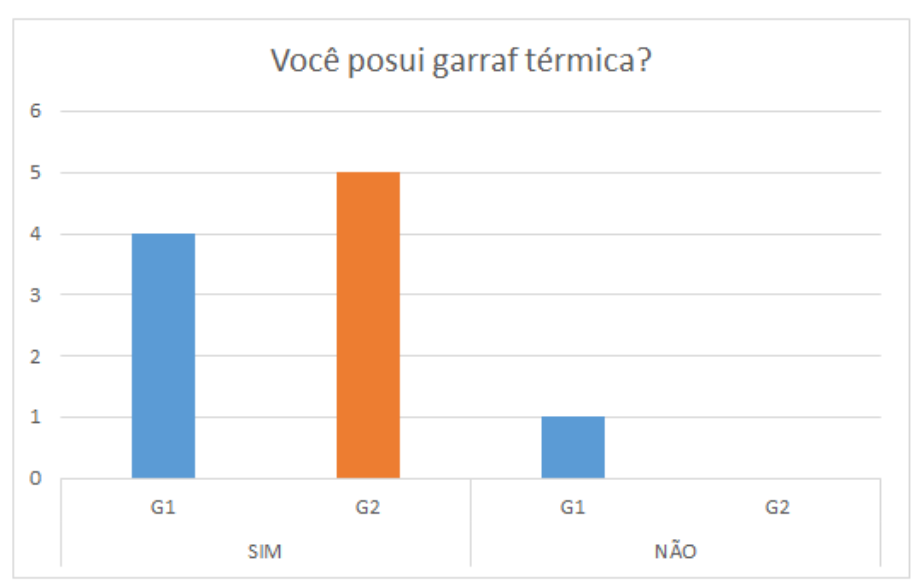

Do total de sujeitos pesquisados, apenas 1 (um) não possuía garrafa térmica em casa, no entanto, tem contato com o objeto diariamente.

Fonte: Autores, 2019

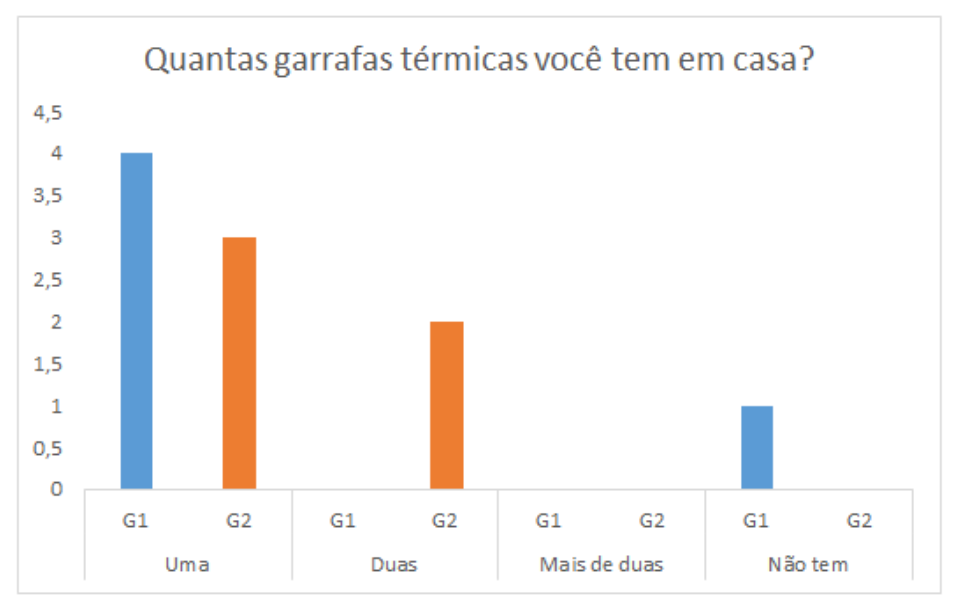

Do total de sujeitos pesquisados, 7 (sete) possuem uma garrafa térmica enquanto apenas 2 (duas) possuem 2 garrafas térmicas em casa.

Imagem 10: modelos destacados por usuários.

Fonte: Autores, 2019. 
$17^{\circ}$ ERGODESIGN \& USIHC 2019

PUC-Rio, 11 a 13 de dezembro

Rio de Janeiro, RJ, Brasil $17^{\circ}$ Ergodesign - Congresso Internacional de Ergonomia e Usabilidade de Interfaces Humano Tecnológica: Produto, Informações Ambientes Construídos e Transporte

$17^{\circ}$ USIHC - Congresso Internacional de Ergonomia e Usabilidade de Interfaces Humano Computador

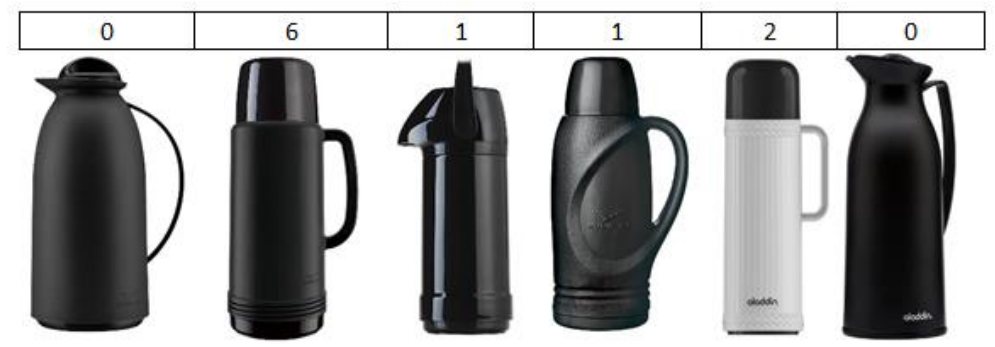

Dos modelos preliminares apresentados as usuárias, seis informaram que o modelo de garrafa que possuem em casa se assemelha à garrafa $n^{\circ} 2$, no entanto, os modelos $n^{\circ}=3,4$ e 5 também foram citados.

Fonte: Autores, 2019.

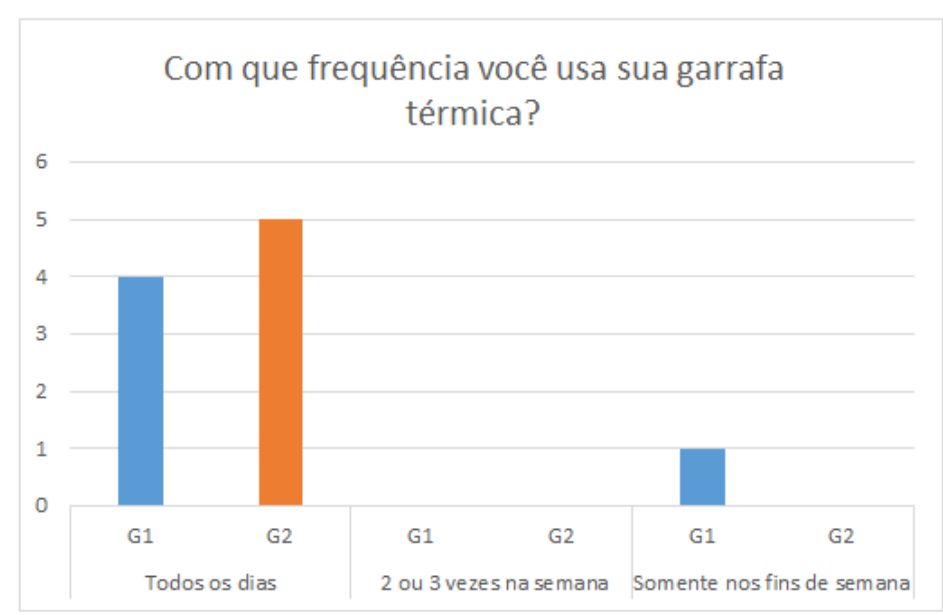

Com relação à frequência de uso das garrafas térmicas, 9 usuárias usam diariamente.

Fonte: Autores, 2019. 
$17^{\circ}$ ERGODESIGN \& USIHC 2019

PUC-Rio, 11 a 13 de dezembro

Rio de Janeiro, RJ, Brasil $17^{\circ}$ Ergodesign - Congresso Internacional de Ergonomia e Usabilidade de Interfaces Humano Tecnológica: Produto, Informações Ambientes Construídos e Transporte

$17^{\circ}$ USIHC - Congresso Internacional de Ergonomia e Usabilidade

de Interfaces Humano Computador

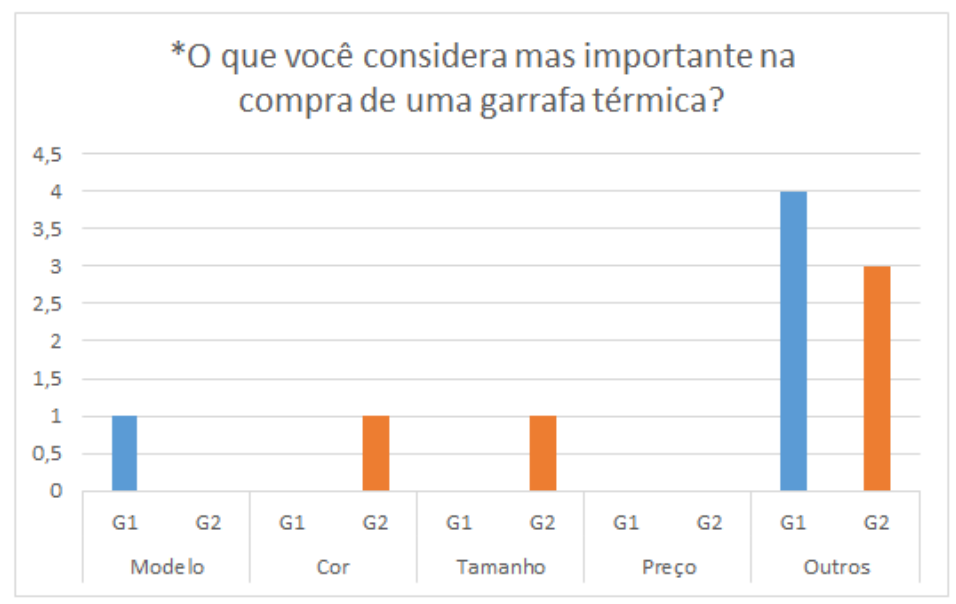

Quando questionadas sobre que critérios seriam mais importantes na escolha de uma garrafa térmica, a opção outros teve maior destaque pelos dois grupos, além das opções previamente definidas (modelo, cor, tamanho e preço), nos informando que o principal fator de sua escolha é a ampola (parte interna da garrafa), pois para elas, a ampola seria responsável por manter a temperatura do líquido. Nenhuma mencionou a opção preço.

Fonte: Autores, 2019.

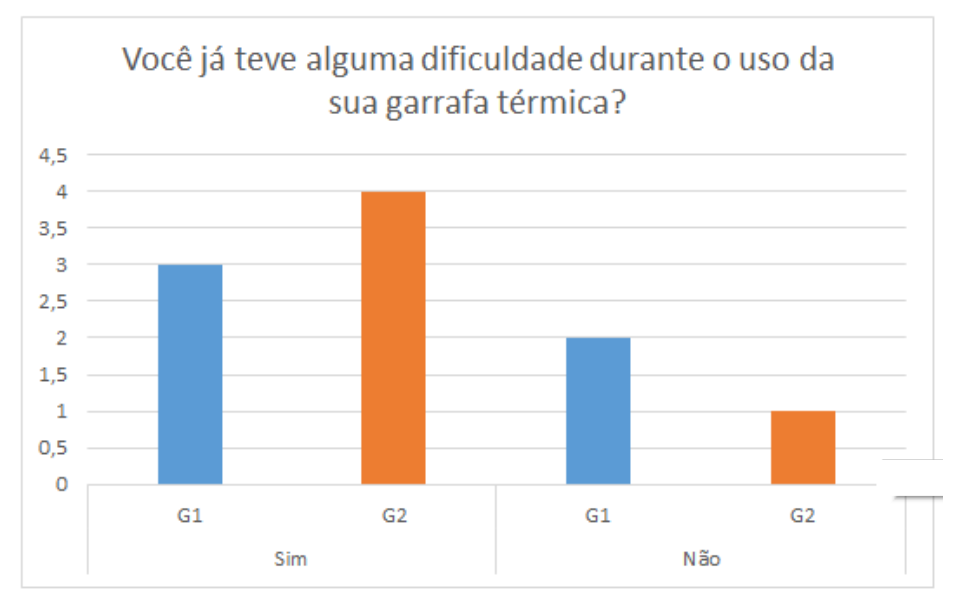

Quando questionadas sobre alguma dificuldade de uso de garrafas térmicas, do total de participantes pesquisadas, mais da metade (7), assumem já ter tido dificuldade em algum momento. Estas mencionaram dificuldades para lavar internamente e para abrir devido ao modelo da garrafa. 
P02: Nível de dificuldade de realização da tarefa

Pedimos as participantes que realizassem as seguintes tarefas:

1. Simular o preparo de um café;

2. Abrir a garrafa térmica e colocar o café no interior da garrafa;

3. Servir o café na xícara;

4. Fechar a garrafa após servir o café na xícara.

Imagem 11: Identificação das garrafas para controle dos moderadores.

Fonte: Autores, 2019.

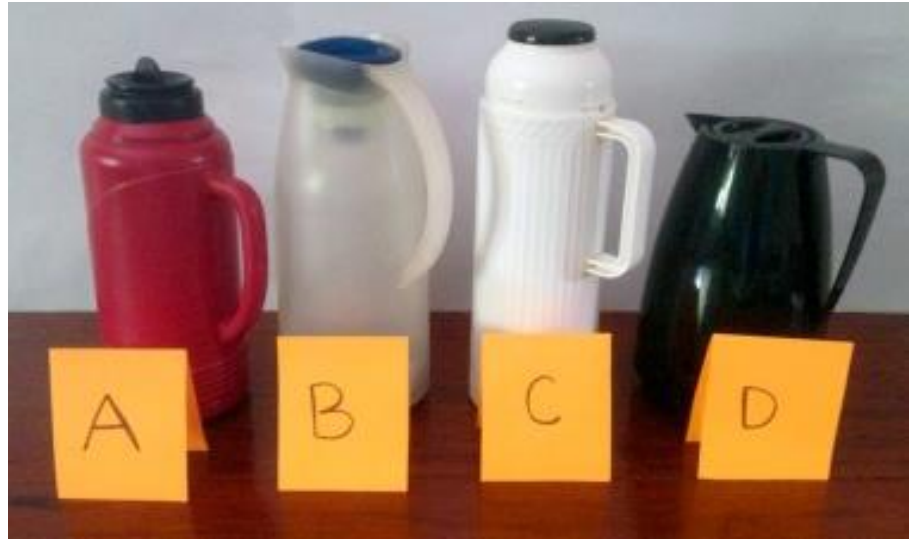

No entanto, consideramos para esta análise, apenas a tarefa 2 , onde obtivemos as seguintes respostas:

Fonte: Autores, 2019.

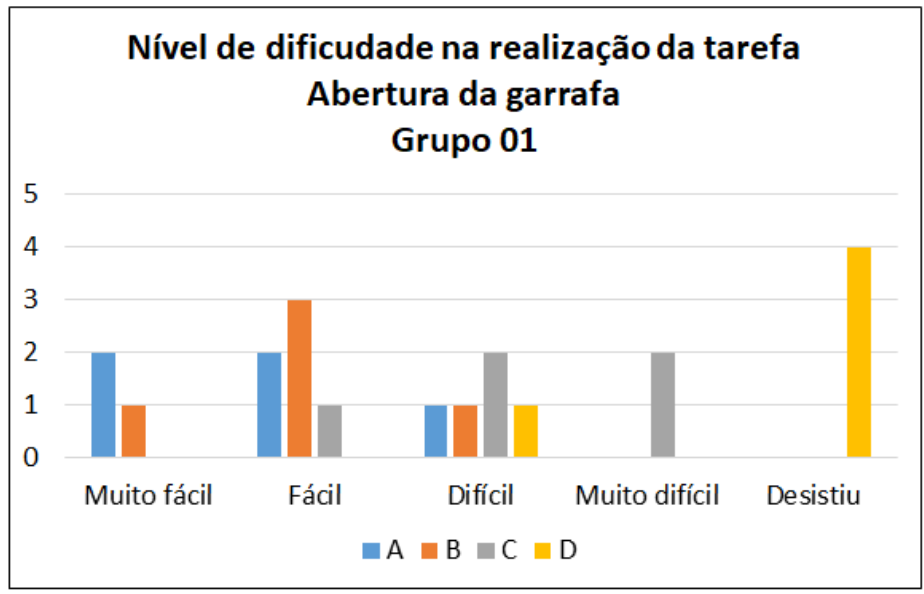

Quanto à tarefa de abertura, as usuárias do $\mathrm{G} 1$, consideram os modelos $\mathrm{A}$ e $\mathrm{B}$ como os mais fáceis de abrir, variando entre Muito fácil e Fácil. Enquanto as garrafas $C$ e $D$ foram consideradas as mais difíceis. Com relação à abertura da garrafa $\mathrm{D}$, houve 4 (quatro) desistências na realização desta tarefa. 
$17^{\circ}$ ERGODESIGN \& USIHC 2019

PUC-Rio, 11 a 13 de dezembro

Rio de Janeiro, RJ, Brasil $17^{\circ}$ Ergodesign - Congresso Internacional de Ergonomia e Usabilidade de Interfaces Humano Tecnológica: Produto, Informações Ambientes Construídos e Transporte

$17^{\circ}$ USIHC - Congresso Internacional de Ergonomia e Usabilidade de Interfaces Humano Computador

Fonte: Autores, 2019

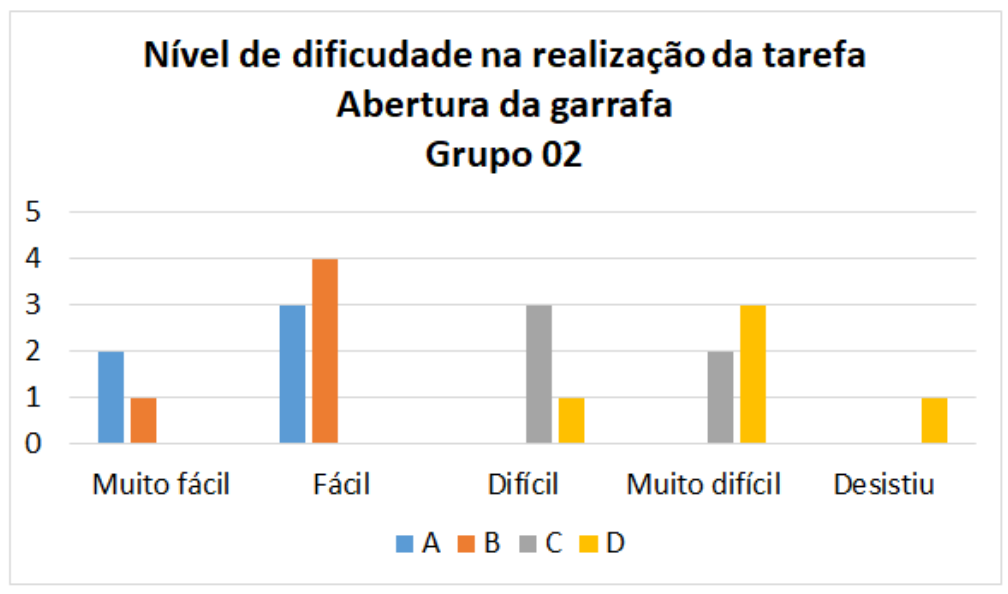

Quanto à tarefa de abertura, as usuárias do G2, também consideram os modelos A e B como os mais fáceis de abrir, variando entre Muito fácil e Fácil. Enquanto as garrafas $C$ e $D$ foram consideradas as mais difíceis. Com relação à abertura da garrafa $\mathrm{D}$, houve uma desistência na realização desta tarefa.

P03: Pós-realização da tarefa - satisfação

Fonte: Autores, 2019

P03: PÓS REALIZAÇÃO DA TAREFA

\begin{tabular}{|c|c|c|c|c|c|c|c|c|c|}
\hline & \multirow[b]{2}{*}{ QUESTÖES } & \multicolumn{4}{|c|}{ GRUPO 1} & \multicolumn{4}{|c|}{ GRUPO 2} \\
\hline & & A & B & C & D & A & B & C & D \\
\hline 1 & Eu usaria essa garrafa diariamente & 2 & & 3 & & 3 & & 2 & \\
\hline 2 & Esta garrafa foi a mais dificil de abrir & & & & 5 & & & 2 & 3 \\
\hline 3 & Esta garrafa foi a mais facil de abrir & 5 & & & & 5 & & & \\
\hline 4 & Eu precisaria de ajuda para abrir esta garrafa & & & 1 & 4 & & & 2 & 3 \\
\hline 5 & Eu usaria essa garrafa em minha casa & 2 & & 3 & & 1 & & 3 & 1 \\
\hline 6 & Usei menos força para abrir esta garrafa & 3 & & 2 & & 5 & & & \\
\hline 7 & Usei mais força para abrir esta garrafa & 1 & & 1 & 3 & & & 3 & 2 \\
\hline 8 & Esta garrafa oferece mais apoio para abrir a tampa & 3 & 1 & 1 & & 4 & & 1 & \\
\hline 9 & Esta garrafa oferece menos apoio para abrir a tampa & & & 1 & 4 & & & 2 & 3 \\
\hline 10 & A tampa desta garrafa demonstra segurança para servir o café & 1 & & 4 & & 1 & & 4 & \\
\hline 11 & Esta garrafa disperdiça mais café & 4 & & 1 & & 3 & 2 & & \\
\hline 12 & Esta garrafa disperdiça menos café & 1 & & 4 & & & & 5 & \\
\hline
\end{tabular}


$17^{\circ}$ ERGODESIGN \& USIHC 2019

PUC-Rio, 11 a 13 de dezembro Rio de Janeiro, RJ, Brasil $17^{\circ}$ Ergodesign - Congresso Internacional de Ergonomia e Usabilidade de Interfaces Humano Tecnológica: Produto, Informações Ambientes Construídos e Transporte

$17^{\circ}$ USIHC - Congresso Internacional de Ergonomia e Usabilidade de Interfaces Humano Computador

Quanto ao item 01: As participantes, dos dois grupos relataram que usariam diariamente as garrafas $\mathrm{A}$ e $\mathrm{C}$;

Quanto ao item 02: O grupo 1 considerou a garrafa D a mais difícil de abrir e para o grupo 2, a garrafa $D$ foi apontada como a mais difícil, seguido da garrafa $C$;

Quanto ao item 03: Por unanimidade ambos os grupos consideraram a garrafa A como a mais fácil de abrir;

Quanto ao item 04: Ambos os grupos afirmaram que precisariam de ajuda para abrir as garrafas C e D;

Quanto ao item 05: O grupo 1 usaria em casa as garrafas $A$ e $C$ enquanto o grupo 2, usariam em casa as garrafas A, C e D;

Quanto ao item 06: O grupo 1 usou menos força nas garrafas A e C, enquanto grupo 2 usou menos força para abrir a garrafa $A$;

Quanto ao item 07: Os grupos 1 e 2 apontaram que usaram mais força para abrir as garrafas $\mathrm{C}$ e D;

Quanto ao item 08: O grupo 1 destacou as garrafas A, B e C como as que proporcionam mais apoio para abrir a tampa, já no grupo 2 foram as garrafas $\mathrm{A}$ e $\mathrm{C}$;

Quanto ao item 09: Para os dois grupos as garrafas C e D oferecem menos apoio para abrir;

Quanto ao item 10: Ambos os grupos destacaram a garrafa C como a que apresenta mais segurança para servir;

Quanto ao item 11: O grupo 1 considerou a garrafa A como a que mais desperdiça e para o grupo 2, os modelos A e B;

Quanto a item 12: Ambos os grupos consideram que a garrafa C desperdiça menos conteúdo.

P04: Percepção de Desconforto/Dor:

Fonte: Autores, 2019.

RESULTADOS PERCEPÇÄO DESCONFORTO/DOR

\begin{tabular}{|c|c|c|c|c|}
\cline { 2 - 5 } \multicolumn{1}{c|}{} & \multicolumn{2}{c|}{ GRUPO 01 } & \multicolumn{2}{c|}{ GRUPO 02 } \\
\hline Sujeitos & Região & Garrafa & Região & Garrafa \\
\hline 1 & $\mathrm{D}, \mathrm{H}, \mathrm{W}$ & $\mathrm{D}$ & $\mathrm{D}, \mathrm{H}$ & $\mathrm{D}$ \\
\hline 2 & $\mathrm{~W}$ & $\mathrm{D}$ & $\mathrm{D}, \mathrm{H}$ & $\mathrm{D}$ \\
\hline 3 & - & - & W, V,D,H & $\mathrm{D}$ \\
\hline 4 & $\mathrm{D}, \mathrm{H}$ & $\mathrm{C}$ & $\mathrm{P}, \mathrm{Q}$ & $\mathrm{C}$ \\
\hline 5 & & & $\mathrm{P}$ & $\mathrm{B}$ \\
\hline
\end{tabular}

_ Não sentiu desconforto/dor 
$17^{\circ}$ ERGODESIGN \& USIHC 2019

PUC-Rio, 11 a 13 de dezembro

Rio de Janeiro, RJ, Brasil $17^{\circ}$ Ergodesign - Congresso Internacional de Ergonomia e Usabilidade de Interfaces Humano Tecnológica: Produto, Informações Ambientes Construídos e Transporte

$17^{\circ}$ USIHC - Congresso Internacional de Ergonomia e Usabilidade

de Interfaces Humano Computador

Imagem 12: Mapa de desconforto das mãos de Kuijt-Evers (2006). Fonte: Adaptada pelos autores, (2019).

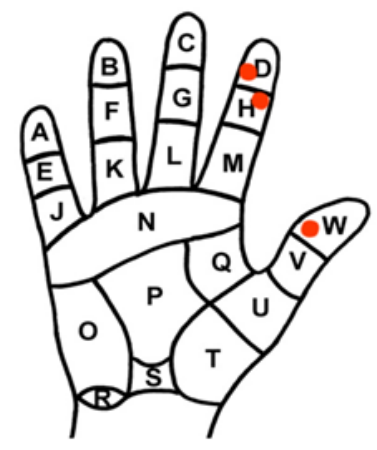

Apontados pelos sujeitos do grupo 01.

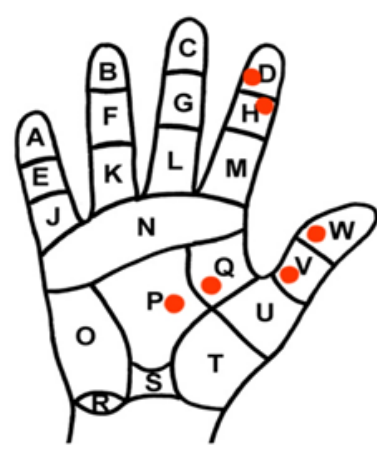

Apontados pelos sujeitos do grupo 02.

Quanto à percepção de desconforto/dor, tomando como base o mapa de Kuijt-Evers (2006), as participantes (todas destras) alegaram desconforto nas seguintes regiões: $O$ grupo 1, apresentou como pontos de desconforto as regiões das pontas dos dedos $(D, H, W)$ ocasionados pelo manuseio dos modelos de garrafas $\mathrm{C}$ e $\mathrm{D}$.

O grupo 2 apresentou como áreas de desconforto as regiões H e D no dedo indicador e W, V no dedo polegar, ambos ocasionados pelo manuseio da garrafa $\mathrm{D}$. Além de informar incomodo nas regiões $\mathrm{P}$ e $\mathrm{Q}$ da palma da mão ocasionados pelo manuseio das garrafas $\mathrm{B}$ e $\mathrm{C}$.

\section{RESULTADOS E DISCUSSÕES}

\subsection{Eficácia:}

Quanto aos modelos de garrafa A e B: Todas as participantes conseguiram cumprir a tarefa designada a estes modelos. Logo, pôde-se considera-las eficazes.

Quanto ao modelo C: Todas as participantes conseguiram realizar a tarefa designada a este modelo. Porém, esta garrafa foi pontuada entre as categorias Difícil e Muito difícil para abrir. Ainda assim, consideramos este modelo eficaz.

Quanto ao modelo D: Este modelo foi considerado ineficaz, pois, das 10 participantes desta pesquisa, 5 desistiram de realizar a tarefa, além disso, as demais participantes (aquelas que concluíram a tarefa) a classificaram entre Difícil e Muito Difícil de abrir. É valido ressaltar que, a maior quantidade de desistências foi do grupo mais jovem, o Grupo 1.

\subsection{Eficiência}

\section{Imagem 13: Média de tempo da realização da tarefa}

Fonte: Autores, 2019. 
$17^{\circ}$ ERGODESIGN \& USIHC 2019

PUC-Rio, 11 a 13 de dezembro

Rio de Janeiro, RJ, Brasil $17^{\circ}$ Ergodesign - Congresso Internacional de Ergonomia e Usabilidade de Interfaces Humano Tecnológica: Produto, Informações Ambientes Construídos e Transporte

$17^{\circ}$ USIHC - Congresso Internacional de Ergonomia e Usabilidade de Interfaces Humano Computador

\begin{tabular}{|c|c|c|c|c|c|c|c|c|}
\hline \multirow{2}{*}{$\begin{array}{c}\text { Media tempo (s) } \\
\text { por grupo }\end{array}$} & \multicolumn{2}{|c|}{$\mathrm{A}$} & \multicolumn{2}{c|}{$\mathrm{B}$} & \multicolumn{2}{|c|}{$\mathrm{C}$} & \multicolumn{2}{|c|}{$\mathrm{D}$} \\
\cline { 2 - 9 } & $\mathrm{G} 1$ & $\mathrm{G} 2$ & $\mathrm{G} 1$ & $\mathrm{G} 2$ & $\mathrm{G} 1$ & $\mathrm{G} 2$ & $\mathrm{G} 1$ & $\mathrm{G} 2$ \\
\cline { 2 - 9 } & 3,5 & 5,44 & 4,3 & 5,8 & 7,82 & 16,03 & 9,15 & 18,33 \\
\hline
\end{tabular}

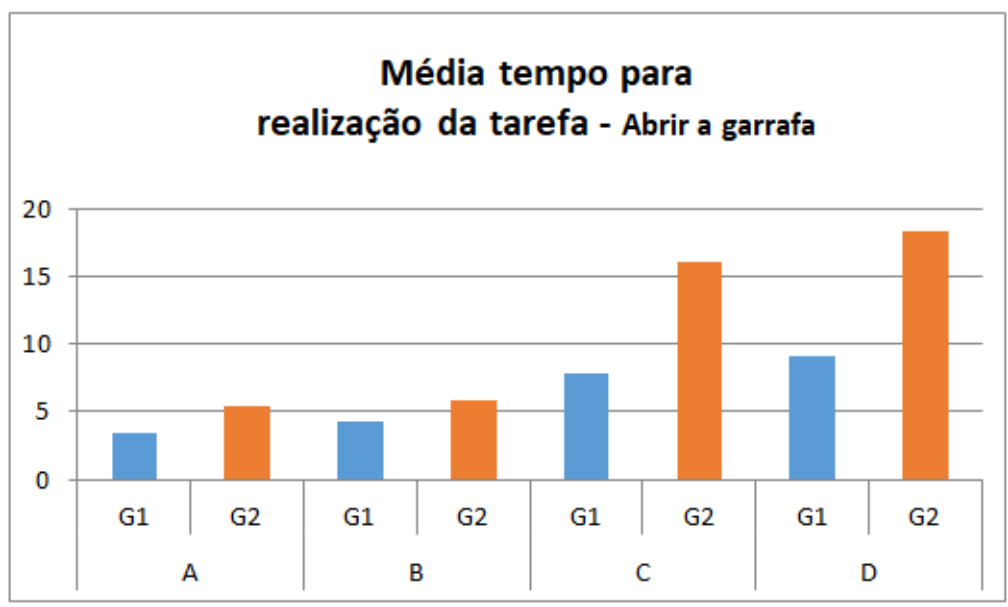

Quanto ao modelo A e B: Ambos os grupos abriram estes modelos no melhor tempo, no entanto o grupo 1 obteve o melhor desempenho.

Quanto ao modelo C e D: O grupo 1 obteve melhor desempenho na abertura das garrafas. O grupo 2, levou quase o dobro do tempo para abri-las. No entanto, é valido ressaltar que houve desistências na realização da tarefa pelos participantes do grupo 1, o que pode justificar 0 maior tempo na realização da tarefa pelo grupo 2, que realizou a tarefa inteira.

\subsection{Satisfação}

Os modelos de garrafa $(\mathrm{A}$ e $\mathrm{C}$ ) receberam critérios positivos durante o transcorrer desta pesquisa. Como critérios positivos podemos destacar que estes modelos foram apontados pelas usuárias como aqueles cujas participantes usariam diariamente em casa; os que oferecem mais apoio para abrir a tampa e os que mais oferecem segurança para servir. $O$ modelo de garrafa térmica $A$, foi definido como o que usa menos força no abrir e por unanimidade definida pelos dois grupos como o mais fácil de abrir.

O modelo de garrafa térmica $\mathrm{D}$, por outro lado, recebeu mais critérios negativos quanto ao seu uso. Foi definido pelos dois grupos de usuárias como o mais difícil de abrir, cujas usuárias necessitariam de ajuda neste processo, logo, demanda mais esforço para abri-lo. O modelo $\mathrm{C}$ também foi apontado como o que proporciona menos apoio para abrir. Estes modelos também foram considerados os que mais causaram desconfortos nas mãos das usuárias, especificamente nas regiões das pontas dos dedos.

O modelo de garrafa térmica $B$, foi pouco pontuado nesta pesquisa.

\subsection{Manejo}


Analisando a tarefa realizada pelas usuárias de garrafas térmicas nesta pesquisa, identificamos os dois tipos de manejo, porém, o manejo fino, exerce maior influência no desempenho de uso deste objeto:

Fonte: Autores, 2019.
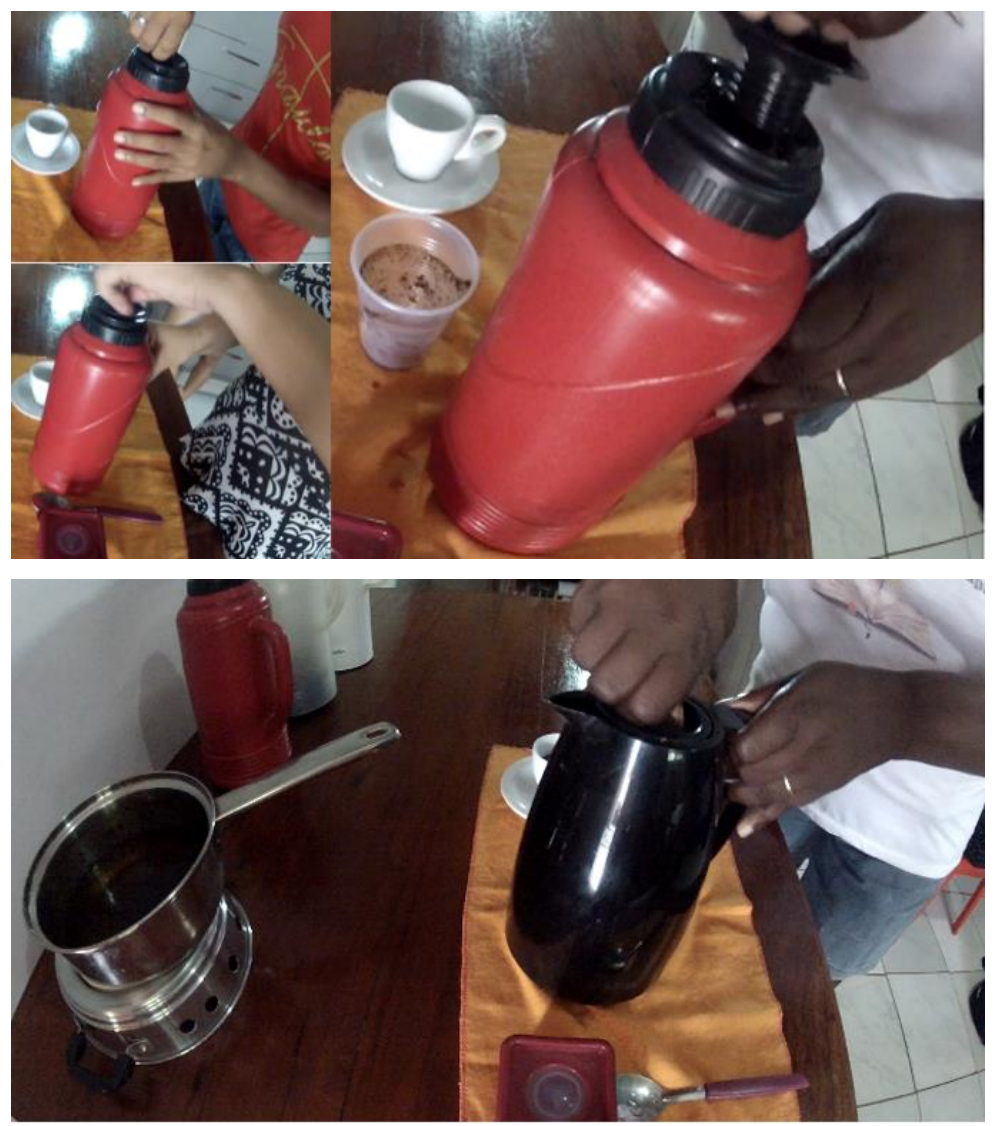

\section{DISCUSSÃO}

O projeto de muitos produtos é dependente de características físicas de seus usuários ou grupos de usuários, envolvendo aspectos com força, tamanho, peso, gênero e questões cognitivas (JORDAN, 1998). Para que esses produtos funcionem bem em suas interações com os usuários ou consumidores, eles devem possuir qualidade técnica, qualidade ergonômica e qualidade estética (IIDA, 2005).

Ademais, para Torres (2009), o design e a ergonomia consideram diversos critérios essenciais para o desenvolvimento de produtos, como: forma, função, usabilidade, especificação de materiais, processos de fabricação, dentre outros. Todos com o objetivo de proporcionar o bemestar do usuário na utilização do produto.

Sendo assim, nesta pesquisa foi possível perceber que o desenho (modelo) da garrafa térmica e de seus componentes (tampa tipo rosca, ampola e alça) são de suma importância para o 


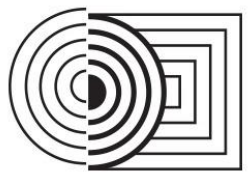

\section{$17^{\circ}$ ERGODESIGN \& USIHC 2019 \\ PUC-Rio, 11 a 13 de dezembro \\ Rio de Janeiro, RJ, Brasil}

$17^{\circ}$ Ergodesign - Congresso Internacional de Ergonomia e Usabilidade

de Interfaces Humano Tecnológica: Produto, Informações Ambientes

Construídos e Transporte

$17^{\circ}$ USIHC - Congresso Internacional de Ergonomia e Usabilidade

de Interfaces Humano Computador

funcionamento deste produto e têm relação direta com o bom ou mau desempenho de sua utilização pelo usuário.

Com tudo, o desenho da tampa e alça da garrafa térmica, tem forte influência no funcionamento e manipulação do objeto, pois o usuário, na maioria dos modelos, precisa rosqueá-la com as pontas dos dedos de uma mão, ou seja, utilizando manejo fino e segura-la com a outra mão, manejo grosseiro, porém constatou-se que a maioria dos modelos de garrafas térmicas analisados não proporcionam estabilidade necessária para que o usuário consiga abri-la facilmente. lida (2005, p.244), comenta que "quando em um mesmo objeto forem necessários os dois tipos de manejo, é adequado que se possa agarrar de diferentes maneiras".

Foi possível perceber que tampa impacta diretamente sobre a postura de uso do produto, como o ângulo de flexão do punho, a pressão exercida sobre as pontas dos dedos, a carga exercida sobre a mão, possíveis fadiga e riscos de lesões como indicadas na imagem 14.

Lewis e Narayan (1993), enfatizam que outro fator importante é a pega, destacando que a forma da pega é um fator primário que pode ser utilizado para reduzir ou eliminar a fadiga do usuário. Enquanto, Kroemer e Grandjean (2008), explicam a importância do design no desenvolvimento de empunhaduras. Para os autores, pegas que não se ajustam adequadamente às mãos, ou não favorecem a biomecânica no trabalho manual, podem prejudicar o desempenho ou ocasionar problemas ao operador.

Por conseguinte, para Borghi e Mejia (2016), as características a serem consideradas na pega incluem: as diferentes formas de pega; os movimentos a serem transmitidos (força, velocidade e precisão), possibilidade de usar as duas mãos (para aumentar a força ou precisão); e se é adaptável aos canhotos.

Já lida (2005), dialoga complementando que os indivíduos apresentam precisão, velocidade e desempenho muscular elevados quando realizam tarefas utilizando a mão dominante, porém deve-se considerar que os canhotos constituem $10 \%$ da população mundial. Portanto, é de significativa importância que ao se desenvolver projetos de produto, que utilizam as mãos como principal forma de manuseio, leve-se em consideração as pessoas destras e canhotas, buscando formas que possibilitem conforto para ambas.

Além disso, o mau dimensionamento de garrafas térmicas pode proporcionar diversos constrangimentos ao usuário, como a insatisfação e desconforto no uso do produto - como mencionado pelas usuárias nesta pesquisa - até doenças por esforço repetitivo. Segundo Paschoarelli et al (2010), quando se relaciona a antropometria da mão humana a ergonomia de instrumentos manuais, "os problemas mais recorrentes estão relacionados à inadequação de dimensionamento, forma, peso, textura e estabilidade". Foi possível perceber que nas garrafas térmicas analisadas, estes critérios são ineficientes.

Todas as garrafas utilizadas mostraram-se ruins para as usuárias rosquearem a tampa. Porém as garrafas $\mathrm{C}$ e $\mathrm{D}$, se mostraram as mais difíceis de abrir. A garrafa $\mathrm{C}$ apresenta a tampa com dimensão pequena, não se adequando a mão das usuárias. $E$ a garrafa $D$, possui a tampa interna a garrafa, tendo a usuária que utilizar as pontas dos dedos para rosquea-la, porém a cavidade para o apoio dos dedos é insuficiente para que se exerça a força necessária para abrila. 
$17^{\circ}$ ERGODESIGN \& USIHC 2019

PUC-Rio, 11 a 13 de dezembro

Rio de Janeiro, RJ, Brasil $17^{\circ}$ Ergodesign - Congresso Internacional de Ergonomia e Usabilidade de Interfaces Humano Tecnológica: Produto, Informações Ambientes Construídos e Transporte

$17^{\circ}$ USIHC - Congresso Internacional de Ergonomia e Usabilidade de Interfaces Humano Computador

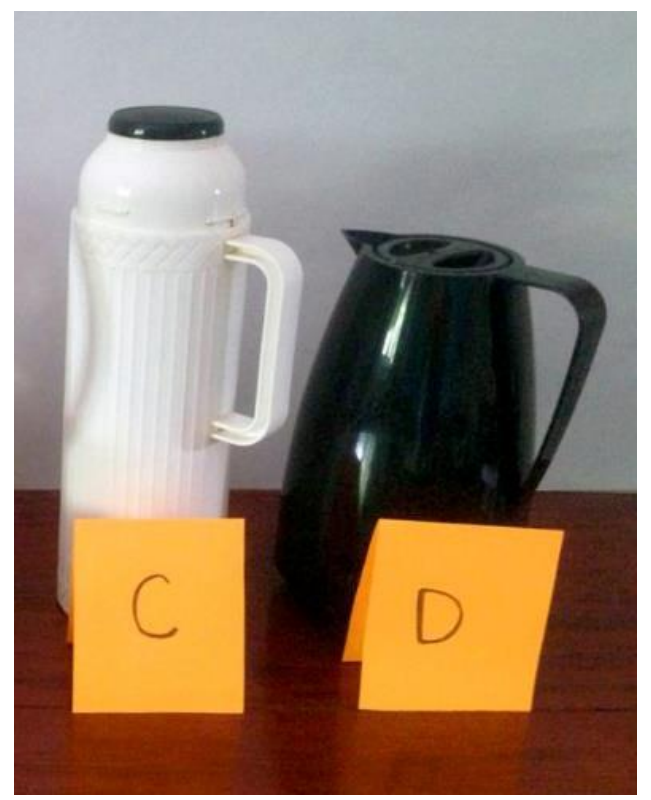

Outro fator observado é o pouco uso de textura nas tampas das garrafas. Dos quatro modelos utilizados, apenas uma possuía textura na tampa, que possibilitava estabilidade na pega para as usuárias. Podemos assim dizer que a inserção de hachuras, frisos nas tampas de garrafas térmicas poderia ser um fator auxiliador na hora da abertura. Pois, segundo Paschoarelli e Coury (2000), a textura permite a fricção entre a mão e o equipamento.

Por tanto, como recomendações de possíveis melhorias, propõem-se o redesign dos componentes deste produto, considerando todas as premissas da ergonomia destacadas, através de um trabalho conjunto com usuários - os que fazem uso deste objeto várias vezes ao dia - com intuito de ouvi-los, considerando suas reais necessidades.

\section{CONSIDERAÇÕES FINAIS}

No transcorrer desta pesquisa pôde-se observar o quanto o uso de garrafas térmicas é importante para o cotidiano das pessoas, em diferentes espaços, no entanto, no sistema de produção destes utensílios, aspectos importantes são deixados de lado, ocasionando produtos mal projetados e por sua vez, que sujeitam seus usuários a riscos.

Neste contexto, o trabalho em torno da usabilidade se torna fundamental, pois através de uma análise de tarefa simples como podemos ilustrar nesta pesquisa - com o uso de garrafas térmicas - pode-se contribuir significante para tornar a vida das pessoas melhores com relação ao uso destes produtos

O papel do design é conciliar a forma e a função desse objeto, proporcionando uma relação propositiva com o usuário. E, em um processo de retroalimentação, as intervenções no produto tendem a diminuir acabam, inclusive, por otimizar suas funções.

\subsection{Desdobramentos de pesquisa}


Como sugestões para pesquisas futuras a partir desta, propomos:

- Realização desta pesquisa comparando resultados entre usuários do sexo feminino e masculino;

- Teste de usabilidade comparando o tamanho da mão dos usuários e sua influência no uso;

- Teste de usabilidades comparando os resultados entre os três modelos de garrafas térmicas classificadas pelo tipo de servir (Rosca, Pressão e Flip).

- Padronização da força aplicada no fechamento das garrafas térmicas antes da realização da tarefa;

- Teste de usabilidade com participantes que usam várias vezes por dia a garrafa térmica em ambientes laborais, como os copeiros, para investigar a percepção de desconforto/dor.

\section{REFERÊNCIAS BIBLIOGRÁFICAS}

BORGHI, Paula Araújo; MEJIA, Dayana Priscila Maia. Ergodesign de ferramentas manuais. 2016.

IIDA, I. Ergonomia: projeto e produção. Edição rev. e ampliada. - São Paulo: Edgard Blücher, 2005.

INMETRO, Instituto Nacional de Metrologia, Qualidade e Tecnologia. Programa de Análise de Produtos: relatório sobre análise em garrafas térmicas para uso doméstico. Divisão de Orientação e Incentivo à Qualidade - Diviq, Diretoria de Avaliação da Conformidade - Dconf. Rio de Janeiro, Março, 2016.

JORDAN, Patrick W. An introduction to usability. London: Taylor \& Francis, 1998.

JORDAN, Patrick W. What is usability? In: ROBERTSON, S. (Ed.) Contemporary ergonomics. London: Taylor \& Francis, 1994. pp. 454-458. >

KUIJT-EVERS, L. F. M. Comfort in Using Hand Tools Theory, Design and Evaluation. [Tese de Doutorado]. Delft: Universidade Técnica de Delft, 2006.

KRUG, Steve. Don't make me think: a common sense approach to web usability. New Riders, 2000, pg.05.

LEWIS, W.; NARAYAN, C. Design and sizing of ergonomic handles for hand tools. Applied Ergonomic, v. 24, n. 5, 1993.

NORDIN, M.; FRANKEL, V. H. Biomecânica básica do sistema musculoesquelético. 3. ed. Rio de Janeiro: Guanabara Koogan, 2003.

PASCOARELLI, L.; COURY, H. Aspectos Ergonômicos e de Usabilidade no Design de Pegas e Empunhaduras. Estudos em Design, Rio de Janeiro, v. 8, n. 1, 2000.

PASCHOARELLI et al. Antropometria da Mão Humana: Influência do Gênero no Design Ergonômico de Instrumentos Manuais ação ergonômica, volume 5, número 2, 2010.

ROEPKE, Giorgia Amir Longo, Et al. A importância da ambientação na avaliação da usabilidade de produtos. In: II Conferência Internacional de Integração do Design, Engenharia e Gestão para a inovação. pg.21-23, Outubro, Florianópolis, SC, Brasil 2012. 
STANTON, N A. \& BARBER, C. Error by design: methods for predicting device usability. Design Studies. Vol. 23, № 4. London, Elsevier Science Ltd, July - 2002. p. 363 -384, 2002.

TOSCANO, W. Métricas de usabilidade. Exacta, São Paulo, v. 4, n. especial, pg.79-80, 25 nov. 2006.

RODRIGUES, Margarida Isabel Mesquita Montes. Desenvolvimento de uma Garrafa Termoelétrica. Dissertação de Mestrado. Programa de Pós-Graduação em Engenharia e Design de Produto, Universidade de Aveiro, Portugal, 2013.

TORRES, F. Análise do ergodesign em empresas exportadoras de móveis nos pólos moveleiros de Bento Gonçalves (RS) e Ubá (MG). Tese de doutorado em ciência florestal, Universidade Federal de Viçosa, MG. 2009.

TULLIS, Thomas; ALBERT, Willian. Measuring the user experience: collecting, analyzing, and presenting usability metrics. Burlington: Morgan Kaufman, 2008.

UEPA, User Experience Professionals Association. Disponível em: www.https://uxpa.org/. Acesso em 10 de janeiro de 2019.

\section{AGRADECIMENTOS}

À Coordenação de Aperfeiçoamento de Pessoal de Nível Superior - Brasil (CAPES) Código de Financiamento 001.

À Fundação de Amparo à Pesquisa e ao Desenvolvimento Científico e Tecnológico do Maranhão - FAPEMA. 